Target article: Osiurak and Reynaud

Word counts: abstract (60 words), main text (995), references (1191), entire text (2356)

\title{
New Caledonian crows afford invaluable comparative insights into human cumulative technological culture
}

Christian Rutz ${ }^{\mathrm{a}, \mathrm{b}}$ and Gavin R. Hunt ${ }^{\mathrm{c}}$

${ }^{a}$ Centre for Biological Diversity, School of Biology, University of St Andrews, St Andrews KY16 9TH, UK;

${ }^{\text {b}}$ Radcliffe Institute for Advanced Study, Harvard University, Cambridge MA 02138, USA; and 'Unaffiliated.

+1 6178996744 (C.R.)

christian.rutz@st-andrews.ac.uk

grhunt10@hotmail.com

https://aviantooluse.org

\begin{abstract}
The New Caledonian crow may be the only non-primate species exhibiting cumulative technological culture. Its foraging tools show clear signs of diversification and progressive refinement, and it seems likely that at least some tool-related information is passed across generations via social learning. Here, we explain how these remarkable birds can help us uncover the basic biological processes driving technological progress.
\end{abstract}

Cumulative culture - the social transmission and accumulation of innovations across generations - has enabled humans to develop technologies of astonishing complexity (Boyd \& Richerson 1996). Osiurak and Reynaud (O\&R) present a timely re-evaluation of the potential cognitive capacities enabling this process, shifting the focus from social-learning to technical-reasoning skills. We enjoyed O\&R's fresh perspective, but were surprised that they did not examine more carefully their starting assumption that only humans possess cumulative technological culture. Two non-human species have been suggested to refine their foraging tools in a cumulative manner - one of our closest relatives, the chimpanzee, and a tropical corvid, the New Caledonian crow (Dean et al. 2014). While O\&R mention New Caledonian crows in passing, we feel they have missed a valuable opportunity to consult the large body of evidence available for this non-primate model system. Here, we provide some of this missing context, and argue that debates about cumulative technological culture benefit greatly from the comparative insights afforded by these remarkable birds.

According to a recent consensus definition (Mesoudi \& Thornton 2018), the New Caledonian crow is a compelling candidate for cumulative technological culture (Hunt \& Uomini 2016; St Clair et al. 2018). A detailed evaluation is beyond the scope of this commentary and will be provided elsewhere, but the key points can be summarised as follows. First, New Caledonian crows' technology exhibits clear signs of cumulative refinement. In addition to using unmodified sticks and other objects, the species actively manufactures two elaborate tool types from living plant material: hooked stick tools and barbed leaf tools (Hunt 1996; Rutz \& St Clair 2012). For both of these, distinct variants have been described that strongly suggest past accumulation of design innovations, progressing from basic to increasingly complex tools (Hunt \& Gray 2003; St Clair \& Rutz 2013). Second, controlled experiments have recently demonstrated that hooked stick tools are much better for extracting prey across a variety of foraging scenarios than (the presumably ancestral) non-hooked stick tools (St Clair et al. 2018), and that well-crafted, deep hooks are particularly efficient (Sugasawa et al. 
2017). Third, it seems likely that at least some tool-related information is passed across generations via social learning, leading to a rudimentary form of material culture, with striking regional variation in tool behaviour (Hunt \& Gray 2003; St Clair et al. 2016; see also Bluff et al. 2010a). Here, the evidence is weaker (review: Rutz et al. 2018), but field studies have shown that juvenile crows hone their tool-related skills during an unusually long dependency period (Bluff et al. 2010b; Hunt et al. 2012), which affords abundant opportunities to observe experienced adults (e.g., Holzhaider et al. 2010; Rutz et al. 2012; St Clair et al. 2015), and laboratory experiments confirmed a capacity to learn both from demonstrators (Kenward et al. 2006; Logan et al. 2015) and artefacts (Jelbert et al. 2018).

O\&R identified technical-reasoning skills as a potential cognitive prerequisite of cumulative technological culture. New Caledonian crows' tool repertoire is obviously rudimentary compared to human technology, consisting entirely of one-piece artefacts crafted from plant materials, but the system allows us to chart the minimal cognitive capacities required for the accumulation of design improvements. Some 20 years of research on the species' tool-related cognition provide instructive insights. New Caledonian crows have been shown: to make and/or select task-appropriate tools (e.g., Chappell \& Kacelnik 2002, 2004; Bluff et al. 2007, 2010b; Knaebe et al. 2017), most likely relying on simple 'heuristics' (Hunt et al. 2006; G.R. Hunt, unpubl. data); to attend to different tool design features (St Clair \& Rutz 2013; Knaebe et al. 2015; but see Holzhaider et al. 2008); and to learn quickly - and even invent - novel tool behaviours (review: Rutz 2020). While these skills are impressive, reports of more advanced cognitive abilities have routinely been contested. This includes claims that New Caledonian crows are capable of: tool-related causal reasoning (pro: Taylor et al. 2011; contra: Ghirlanda \& Lind 2017; Hennefield et al. 2018); analogical reasoning in the context of sequential tool use (pro: Taylor et al. 2007; contra: Wimpenny et al. 2009; and see: Taylor et al. 2010); making inferences about hidden causal agents (pro: Taylor et al. 2012; contra: Boogert et al. 2013; Dymond et al. 2013); creating novel causal interventions (pro: Jacobs et al. 2014; contra: Taylor et al. 2014; and see: von Bayern et al. 2009); adaptively fashioning new tool shapes (pro: Weir et al. 2002; contra: Rutz et al. 2016); and using mental representations to solve tool problems (pro: Gruber et al. 2019; contra: Vonk 2019). This ambiguity may partly reflect the methodological challenges inherent in probing the minds of non-verbal subjects, but in our view, it also brings into focus the upper limits of the species' reasoning abilities.

In conclusion, New Caledonian crows excel at solving tool-related tasks, exhibiting a clear capacity for quick learning and behavioural flexibility, but evidence of more advanced cognitive abilities is much weaker. This suggests that a rudimentary form of cumulative technological advancement is possible without some of the technical-reasoning skills O\&R predicted to be essential (as well as without language and active teaching; see Bluff et al. 2010a; Holzhaider et al. 2010). If our preliminary assessment is correct, it would raise the possibility that cognitive constraints are currently limiting the scope for further technological advancement in New Caledonian crows, and/or that different mechanisms enable cumulative technology in humans and New Caledonian crows. While non-cultural processes are expected to contribute to shaping the technology of New Caledonian crows (Kenward et al. 2005; Rutz et al. 2018), we should not underestimate the extent to which this was also the case in our tool-making ancestors (e.g., Corbey et al. 2016). So, whatever the precise contributions of genetics, individual learning and social transmission (Hunt \& Uomini 2016; Rutz et al. 2018), the New Caledonian crow - and other non-human tool users (e.g., Rutz et al. 2016) - provide a powerful comparative framework (Dean et al. 2014) for identifying the basic biological processes that enable cumulative technological evolution.

Acknowledgements: We thank Barbara Klump, Phil Shaw and Matthew Steele for constructive comments. 
Conflicts of interest: None.

Funding: C.R. drafted this commentary whilst being the grateful recipient of a Radcliffe Fellowship at the Radcliffe Institute for Advanced Study, Harvard University, USA. G.R.H.'s contributions to the development and editing of the manuscript were self-funded.

\section{References}

Bluff L.A., Kacelnik A. \& Rutz C. (2010a) Vocal culture in New Caledonian crows Corvus moneduloides. Biol. J. Linn. Soc. 101:767-776.

Bluff L.A., Troscianko J., Weir A.A.S., Kacelnik A. \& Rutz C. (2010b) Tool use by wild New Caledonian crows Corvus moneduloides at natural foraging sites. Proc. R. Soc. B 277:1377-1385.

Bluff L.A., Weir A.A.S., Rutz C., Wimpenny J.H. \& Kacelnik A. (2007) Tool-related cognition in New Caledonian crows. Comp. Cogn. Behav. Rev. 2:1-25.

Boogert N.J., Arbilly M., Muth F. \& Seed A.M. (2013) Do crows reason about causes or agents? Proc. Natl Acad. Sci. USA 110:E273.

Boyd R. \& Richerson P.J. (1996) Why culture is common, but cultural evolution is rare. Proc. Brit. Acad. 88:77-93.

Chappell J. \& Kacelnik A. (2002) Tool selectivity in a non-mammal, the New Caledonian crow (Corvus moneduloides). Anim. Cogn. 5:71-78.

Chappell J. \& Kacelnik A. (2004) Selection of tool diameter by New Caledonian crows Corvus moneduloides. Anim. Cogn. 7:121-127.

Corbey R., Jagich A., Vaesen K. \& Collard M. (2016) The Acheulean handaxe: more like a bird's song than a Beatles' tune? Evol. Anthropol. 25:6-19.

Dean L.G., Vale G.L., Laland K.N., Flynn E. \& Kendal R.L. (2014) Human cumulative culture: a comparative perspective. Biol. Rev. 89:284-301.

Dymond S., Haselgrove M. \& McGregor A. (2013) Clever crows or unbalanced birds? Proc. Natl Acad. Sci USA 110:E336.

Ghirlanda S. \& Lind J. (2017) 'Aesop's fable' experiments demonstrate trial-and-error leaning in birds, but no causal understanding. Anim. Behav. 123:239-247.

Gruber R., Schiestl M., Boeckle M., Gray R.D., Clayton N.S. \& Taylor A.H. (2019) New Caledonian crows use mental representations to solve metatool problems. Curr. Biol. 29:686-692.

Hennefield L., Hwang H.G., Weston S.J. \& Povinelli D.J. (2018) Meta-analytic techniques reveal that corvid causal reasoning in the Aesop's Fable paradigm is driven by trial-and-error learning. Anim. Cogn. 21:735-748.

Holzhaider J.C., Hunt G.R., Campbell V.M. \& Gray R.D. (2008) Do wild New Caledonian crows (Corvus moneduloides) attend to the functional properties of their tools? Anim. Cogn. 11:243-254.

Holzhaider J.C., Hunt G.R. \& Gray R.D. (2010) Social learning in New Caledonian crows. Learn. Behav. 38:206-219.

Hunt G.R. (1996) Manufacture and use of hook-tools by New Caledonian crows. Nature 379:249-251.

Hunt G.R. \& Gray R.D. (2003) Diversification and cumulative evolution in tool manufacture by New Caledonian crows. Proc. R. Soc. B 270:867-874.

Hunt G.R., Holzhaider J.C. \& Gray R.D. (2012) Prolonged parental feeding in toolusing New Caledonian crows. Ethology 118:423-430.

Hunt G., Rutledge R. \& Gray R. (2006) The right tool for the job: what strategies do wild New Caledonian crows use? Anim. Cogn. 9:307-316.

Hunt G.R. \& Uomini N. (2016) A complex adaptive system may be essential for cumulative modifications in tool design. Jpn J. Anim. Psychol. 66:141-159.

Jacobs I.F., von Bayern A., Martin-Ordas G., Rat-Fischer L. \& Osvath M. (2014) Corvids create novel causal interventions after all. Proc. R. Soc. B 282:20142504.

Jelbert S.A., Hosking R.J., Taylor A.H. \& Gray R.D. (2018) Mental template matching is a potential cultural transmission mechanism for New Caledonian crow tool manufacturing traditions. Sci. Rep. 8:8956.

Kenward B., Rutz C., Weir A.A.S. \& Kacelnik A. (2006) Development of tool use in New Caledonian crows: inherited action patterns and social influences. Anim. Behav. 72:1329-1343.

Kenward B., Weir A.A.S., Rutz C. \& Kacelnik A. (2005) Tool manufacture by naïve juvenile crows. Nature 433:121.

Knaebe B., Taylor A.H., Elliffe D.M. \& Gray R.D. (2017) New Caledonian crows show behavioural flexibility when manufacturing their tools. Behaviour 154:65-91.

Knaebe B., Taylor A.H., Miller R. \& Gray R.D. (2015) New Caledonian crows (Corvus moneduloides) attend to barb presence during pandanus tool manufacture and use. Behaviour 152:2107-2125. 
Logan C.J., Breen A.J., Taylor A.H., Gray R.D. \& Hoppitt W.J.E. (2015) How New Caledonian crows solve novel foraging problems and what it means for cumulative culture. Learn. Behav. 44:18-28.

Mesoudi A. \& Thornton A. (2018) What is cumulative cultural evolution? Proc. R. Soc. B 285:20180712.

Rutz C. (2020) Tool innovation in crows. (forthcoming book chapter, Cambridge University Press).

Rutz C., Burns Z.T., James R., Ismar S., Burt J., Otis B., Bowen J. \& St Clair J.J.H. (2012) Automated mapping of social networks in wild birds. Curr. Biol. 22:R669-R671.

Rutz C., Hunt G.R. \& St Clair J.J.H. (2018) Corvid technologies: how do New Caledonian crows get their tool designs? Curr. Biol. 28:R1109-R1111.

Rutz C., Klump B.C., Komarczyk L., Leighton R., Kramer J., Wischnewski S., Sugasawa S., Morrissey M.B., James R., St Clair J.J.H., Switzer R.A. \& Masuda B.M. (2016) Discovery of species-wide tool use in the Hawaiian crow. Nature 537:403-407.

Rutz C. \& St Clair J.J.H. (2012) The evolutionary origins and ecological context of tool use in New Caledonian crows. Behav. Processes 89:153-165.

Rutz C., Sugasawa S., van der Wal J.E.M., Klump B.C. \& St Clair J.J.H. (2016) Tool bending in New Caledonian crows. R. Soc. Open Sci. 3:160439.

St Clair J.J.H., Burns Z.T., Bettaney E., Morrissey M.B., Otis B., Ryder B., Fleischer R.C., James R. \& Rutz C. (2015) Experimental resource pulses influence social-network dynamics and the potential for information flow in tool-using crows. Nature Commun. 6:7197.

St Clair J.J.H., Klump B.C., Sugasawa S., Higgott C.G., Colegrave N. \& Rutz C. (2018) Hook innovation boosts foraging efficiency in tool-using crows. Nature Ecol. Evol. 2:441-444.

St Clair J.J.H., Klump B.C., van der Wal J.E.M., Sugasawa S. \& Rutz C. (2016) Strong between-site variation in New Caledonian crows' use of hook-tool-making materials. Biol. J. Linn. Soc. 118:226-232.

St Clair J.J.H. \& Rutz C. (2013) New Caledonian crows attend to multiple functional properties of complex tools. Phil. Trans. R. Soc. B 368:20120415.

Sugasawa S., Klump B.C., St Clair J.J.H. \& Rutz C. (2017) Causes and consequences of tool shape variation in New Caledonian crows. Curr. Biol. 27:3885-3890.

Taylor A.H., Cheke L.G., Waismeyer A., Meltzoff A.N., Miller R., Gopnik A., Clayton N.S. \& Gray R.D. (2014) Of babies and birds: complex tool behaviours are not sufficient for the evolution of the ability to create a novel causal intervention. Proc. R. Soc. B 281:20140837.

Taylor A.H., Elliffe D.M., Hunt G.R., Emery N.J., Clayton N.S. \& Gray R.D. (2011) New Caledonian crows learn the functional properties of novel tool types. PloS One 6:e26887.

Taylor A.H., Elliffe D., Hunt G.R. \& Gray R.D. (2010) Complex cognition and behavioural innovation in New Caledonian crows. Proc. R. Soc. B 277:2637-2643.

Taylor A.H., Hunt G.R., Holzhaider J.C. \& Gray R.D. (2007) Spontaneous metatool use by New Caledonian crows. Curr. Biol. 17:1504-1507.

Taylor A.H., Miller R. \& Gray R.D. (2012) Causal reasoning in New Caledonian crows. Proc. Natl Acad. Sci USA 109:16389-16391.

von Bayern A.M.P., Heathcote R.J.P., Rutz C. \& Kacelnik A. (2009) The role of experience in problem solving and innovative tool use in crows. Curr. Biol. 19:1965-1968.

Vonk J. (2019) Sticks and stones: Associative learning alone? Learn. Behav. https://doi.org/10.3758/s13420-019-00387-4

Weir A.A.S., Chappell J. \& Kacelnik A. (2002) Shaping of hooks in New Caledonian crows. Science 297:981.

Wimpenny J.H., Weir A.A.S., Clayton L., Rutz C. \& Kacelnik A. (2009) Cognitive processes associated with sequential tool use in New Caledonian crows. PLoS One 4:e6471. 